26. Hale DE, Batshaw ML, Coates PM, Frerman FE, Goodman SI, Singh I, Stanley CA 1985 Long-chain acyl coenzyme A dehydrogenase deficiency: an inherited cause of nonketotic hypoglycemia. Pediatr Res 19:666-671

27. Davies SE, Iles RA, Stacey TE, Sousa CD, Chalmers RA 1991 Carnitine therapy and metabolism in the disorders of propionyl-CoA metabolism studied using 1H-NMR spectroscopy. Clin Chim Acta 204:263-277
28. Wolff JA, Carroll JE, Le PT, Prodanos C, Haas R, Nyhan WL 1986 Carnitine reduces fasting ketogenesis in patients with disorders of propionate metabolism. Lancet 1:289-291

29. Corr PB, Creer MH, Yamada KA, Saffitz JE, Sobel BE 1989 Prophylaxis of early ventricular fibrillation by inhibition of acylcarnitine accumulation. $J$ Clin Invest 83:927-936

\title{
Announcement
}

\section{The Australian NHMRC Twin Registry: \\ A Resource for Pediatric Research}

The Australian NHMRC Twin Registry contains more than 4000 pairs of twins under 10 years old and 3000 more up to the age of 18 years. The parents of these twins have volunteered to consider requests from researchers for studies in bona fide projects approved by the Registry. This represents a major resource for studies in pediatric and adolescent epidemiology. There are numerous ways in which twins can be used to address scientific and medical questions. Some examples include examining genetic and environmental variation, co-twin control studies based on disease discordant or exposure discordant pairs, longitudinal studies, and studies of geneenvironment interaction (Clifford and Hopper: The Australian NHMRC Twin Registry. A resource for the Australian scientific community. Med J Aust 60:149, 1986). Although there have been more than 70 projects conducted over the last 12 years on the 17000 adult pairs in the Registry, to date there have been few studies making use of the younger pairs. Baseline information has been computerized on about $50 \%$ of these pairs. Applications to use the Registry can be made from researchers throughout the world. There may be some charge, depending on costs and level of work required by local staff. All applications are reviewed by the Executive Committee of the Registry, and advice on study design and practicalities is available. For more information. contact: Dr. John L. Hopper, Director, Australian NHMRC Twin Registry, 151 Barry Street, Carlton, Victoria 3053, Australia. 